\title{
Hunting pressure modulates the composition and size structure of terrestrial and arboreal vertebrates in Amazonian forests
}

\author{
Andressa B. Scabin ${ }^{1,2}$ (D) Carlos A. Peres ${ }^{2,3}$ (D)
}

Received: 16 November 2020 / Revised: 22 July 2021 / Accepted: 28 July 2021 /

Published online: 5 August 2021

(C) The Author(s) 2021

\begin{abstract}
Overhunting is a leading contemporary driver of tropical forest wildlife loss. The absence or extremely low densities of large-bodied vertebrates disrupts plant-animal mutualisms and consequently degrades key ecosystem services. Understanding patterns of defaunation is therefore crucial given that most tropical forests worldwide are now "half-empty". Here we investigate changes in vertebrate community composition and size structure along a gradient of marked anthropogenic hunting pressure in the Médio Juruá region of western Brazilian Amazonia. Using a novel camera trapping grid design deployed both in the understorey and the forest canopy, we estimated the aggregate biomass of several functional groups of terrestrial and arboreal species at 28 sites along the hunting gradient. Generalized linear models (GLMs) identified hunting pressure as the most important driver of aggregate biomass for game, terrestrial, and arboreal species, as well as nocturnal rodents, frugivores, and granivores. Local hunting pressure affected vertebrate community structure as shown by both GLM and ordination analyses. The size structure of vertebrate fauna changed in heavily hunted areas due to population declines in large-bodied species and apparent compensatory increases in nocturnal rodents. Our study shows markedly altered vertebrate community structure even in remote but heavily settled areas of continuous primary forest. Depletion of frugivore and granivore populations, and concomitant densitycompensation by seed predators, likely affect forest regeneration in persistently overhunted tropical forests. These findings contribute to a better understanding of how cascading effects induced by historical defaunation operate, informing wildlife management policy in tropical peri-urban, rural and wilderness areas.
\end{abstract}

Keywords Wildlife $\cdot$ Mammals $\cdot$ Birds $\cdot$ Defaunation $\cdot$ Density compensation $\cdot$ Camera trapping

Communicated by Sandro Lovari.

Carlos A. Peres

c.peres@uea.ac.uk

Extended author information available on the last page of the article 


\section{Introduction}

Overhunting is the leading driver of contemporary defaunation inducing decisive declines in the abundance of large-bodied vertebrate populations in tropical forests worldwide (Peres and Palacios 2007; Fa and Brown 2009; Harrison et al. 2016). Bird and mammal abundance can decline by over $50 \%$ and $80 \%$, respectively, in heavily hunted tropical forest areas (Benítez-López et al. 2017). In this way, hunting-induced defaunation is a threat that obscures the integrity of both forest biotas and their fabric of ecological interactions (Redford 1992; Wilkie et al. 2011). Beyond potentially severe ecological impacts, defaunation can also aggravate socioeconomic imperatives sustaining local livelihoods and food security of rural peoples for whom wild meat remains a critical non-market source of animal protein (Nielsen et al. 2018; Nunes et al. 2019).

In general, overhunting alters the structure of Neotropical vertebrate communities promoting a directional decline in large-bodied mammal and bird populations (Peres 2000; Jerozolimski and Peres 2003). Downsizing in the community-wide body mass of over 1,000 mammal assemblages across the Neotropics is in the order of $\sim 14 \mathrm{~kg}$ in historical assemblages compared to only $\sim 4 \mathrm{~kg}$ in modern assemblages (Bogoni et al. 2020). On the other hand, small-bodied mammals such as rodents and small primate species can benefit from intensely hunted areas due to release from negative interactions (e.g. predation and resource competition), changes in habitat structure, or both (Peres and Dolman 2000; Galetti et al. 2015a; Young et al. 2015).

Among the trophic guilds most affected by overhunting are frugivores and selective browsers, which are primarily hunted for subsistence and trade (Peres and Palacios 2007; Abernethy et al. 2013). While large carnivores, such as leopards and jaguars, are often persecuted in retaliation for livestock depredation (Michalski et al 2006), their populations may also decline due to hunting-induced co-depletion of prey populations (Ripple et al. 2015). Although several large-bodied arboreal frugivores provide high-quality dispersal services for large-seeded plants (Peres and Roosmalen 2009), studies comparing how either arboreal or terrestrial vertebrates respond to hunting pressure remain scarce.

Arboreal mammals are more susceptible to habitat disturbance, such as forest cover loss, compared to co-occurring terrestrial counterparts, with the greatest negative numerical responses exhibited by key seed dispersal agents (Whitworth et al. 2019). Likewise we also conjectured that arboreal species would be more affected by hunting than their terrestrial counterparts because (1) large arboreal animals are often more vocal and noisier as they move through the canopy, and therefore more detectable; and (2) large primates in our study landscape were historically overhunted during the height of the rubber-boom, and their populations may not have completely recovered despite lower contemporary levels of hunting pressure.

Until recently, large vertebrates have been surveyed mainly through direct observational methods along line-transects, but game species may avoid humans and gradually become less detectable in persistently hunted areas (Fragoso et al. 2016). However, the widespread use of camera traps to survey terrestrial vertebrates, and more recently their arboreal counterparts (Whitworth et al. 2016; Bowler et al. 2017), provide an opportunity to advance our understanding of how hunting affects vertebrate assemblages in relation to forest vertical stratification.

Global analysis suggests that $\sim 50 \%$ of all tropical forest areas is already partially defaunated of large-bodied mammals and $20 \%$ of all protected areas have been affected by hunting, mainly in Africa and Asia (Benítez-López et al. 2019). Although the Neotropics has 
so far experienced intermediate defaunation rates (Fa et al. 2002), some biomes contain a severely depleted contemporary vertebrate fauna, including the Brazilian semiarid Caatinga and the Atlantic Forest (Bogoni et al. 2020). Large-bodied vertebrate depletion has become increasingly pervasive even in some of the most remote parts of the Amazon (Peres and Lake 2003), mainly for the aquatic megafauna like giant otter, manatees and caimans following the massive 20th-century international trade in furs and skins (Antunes et al. 2016). However, terrestrial vertebrate populations in the Amazon are more resilient to overhunting compared to their large-bodied aquatic counterparts, likely because many vast upland areas remain inaccessible to hunters, generating a positive source-sink dynamic that can rescue overharvested populations in heavily hunted areas (Antunes et al. 2016).

Here, we assessed the effects of a quasi-experimental large-scale gradient of hunting pressure in the Médio Juruá region of western Brazilian Amazonia on the community structure of both terrestrial and arboreal forest vertebrates. Our sites included heavily settled peri-urban areas, low-human-density landscapes used by local semi-subsistence communities and vast areas of non-hunted primary forest. We hypothesized that game depletion altered vertebrate community structure by reducing the aggregate biomass of meso and large-bodied mammal and bird species $(>1 \mathrm{~kg}$ ) in heavily hunted areas. In contrast, we expected that the abundance of sympatric small-bodied rodents would increase in overhunted areas where large mammals had been depleted through a mechanism of density compensation, such as competitive release. Furthermore, we hypothesized that arboreal species would be more severely affected by hunting than their terrestrial counterparts, because of the heavier regional-scale hunting pressure on diurnal primates in the past and their higher detectability.

These hypotheses were addressed using a novel camera-trapping design including terrestrial and arboreal surveys at 30 sites distributed throughout a hunting pressure gradient in Médio Juruá river. Our sampling design redresses the limited spatial replication of most hunting impact studies and defines hunting pressure as a continuous rather than a binary or rank variable. We therefore provide evidence on the effects of hunting on tropical forest vertebrate communities through a robustly replicated design.

\section{Material and methods}

\section{Study area}

The study was carried out in the Médio Juruá region of western Brazilian Amazonia (Fig. 1), including two large contiguous sustainable-use protected areas and adjacent landscapes containing two urban clusters. This represents the middle-third section of the Juruá River, the second-longest white-water tributary of the Amazon River. The two protected areas include the 253,227 ha Médio Juruá Extractive Reserve (RESEX Médio Juruá, $5^{\circ} 33^{\prime} 54^{\prime \prime} \mathrm{S}, 67^{\circ} 42^{\prime} 47^{\prime \prime} \mathrm{W}$ ), created in 1997 and legally occupied by 2000 people distributed across 13 villages; and the 632,949 ha Uacari Sustainable Development Reserve (RDS Uacari, $5^{\circ} 43^{\prime} 58^{\prime \prime S}, 67^{\circ} 46^{\prime} 53 " \mathrm{~W}$ ) created in 2005 , where $\sim 1,200$ people occupy 32 villages. The nearest towns are Carauari (population $\approx 28,000$ residents), located 88 fluvial $\mathrm{km}$ downstream of the RESEX Médio Juruá, and Itamarati (population $\approx 8000$ ), located 120 fluvial km upstream of the RDS Uacari (IBGE 2018). The Médio Juruá region has a wet tropical climate with a mean annual temperature of $27.1{ }^{\circ} \mathrm{C}$ and a mean annual rainfall of $3679 \mathrm{~mm}$, with the wettest period between November and April. 


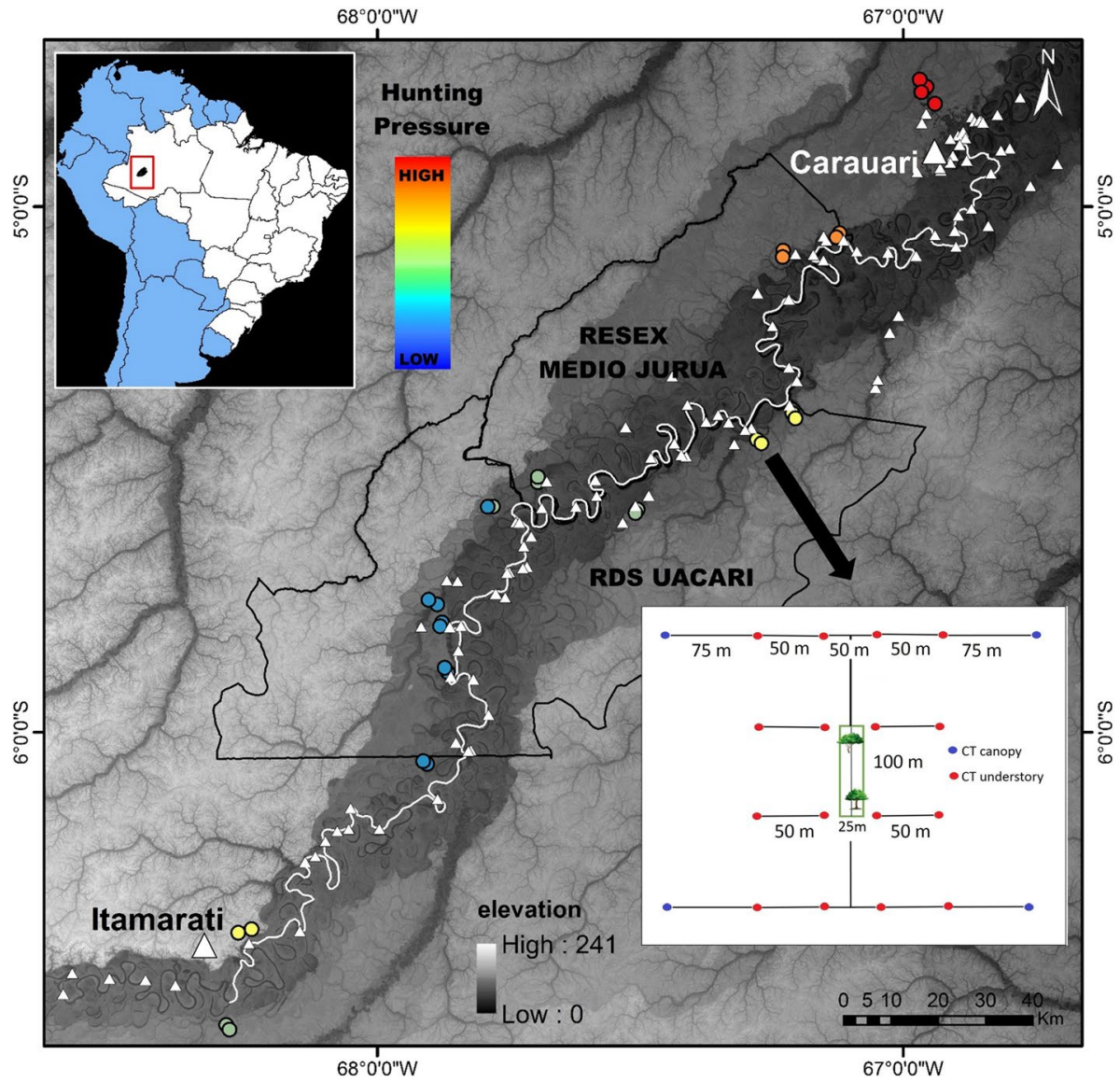

Fig. 1 Map of the study area in the Médio Juruá region of Western Brazilian Amazonia. The reserve boundaries of the RESEX Médio Juruá and RDS Uacari are outlined in black. Coloured circles indicate the location of our 30 sampling grids. Circles are colour-coded according to our proxy of hunting pressure (see colour gradient). The main Juruá River channel is outlined in white. Grey background shows elevation where lighter shading represents higher terrain. The panel on the bottom right is a schematic drawing of the camera trap grid deployment within our study grids. Red and blue circles represent cameras deployed in the understorey and the canopy, respectively. Green rectangle at the center of the camera trapping grid indicates a 0.25 -ha permanent tree plot $(100 \mathrm{~m} \times 25 \mathrm{~m})$

Two different forest types comprise the study landscape: seasonally-flooded (várzea) forests, which account for $\sim 20 \%$ of the study region, characterized by enriched Andean alluvial soils and lower floristic diversity, and the dominant $(\sim 80 \%)$ unflooded forest (terra firme), which exhibits higher floristic diversity and comparatively lower soil fertility (Hawes and Peres 2016). The current study was performed in unflooded forest on paleovárzea sediments, thereafter as terra firme for simplicity, but we recognize that these forests, may diverge in their floristic macromosaics from so-called terra firme forests (Assis et al. 2015). Our sapling sites were established along areas that had experienced subsistence and commercial hunting to varying degrees but had no recent history of clear-cuts, wildfires, and timber extraction. We selected 30 sites spanning a wide gradient of hunting pressure along $600 \mathrm{~km}$ non-linear (fluvial) distance, from the towns of Carauari to 
Itamarati (Fig. 1, Table S1). The sites selection was based on both distance to human settlements, physical accessibility and previous studies carried out in the area by the Médio Juruá Project (PMJ). At each of these 30 sites we established a standardized sampling protocol to obtain data on vertebrate abundance using terrestrial and arboreal camera traps; forest structure and composition; and other environmental variables that potentially influence vertebrate abundance, described as follows.

\section{Terrestrial and arboreal camera trapping}

Terrestrial and arboreal camera trapping were conducted from July 2017 to May 2019. We employed a modified camera-trapping design using a 4.5-ha terrestrial grid containing 16 camera-trap stations $(4 \times 4$, spaced by $100 \mathrm{~m})$, which were combined with four arboreal camera trap-stations (hereafter, CTS) spaced by $300 \mathrm{~m}$. Thus, each of our 30 grids contained 20 cameras (16 terrestrial and 4 arboreal), amounting to total of 480 CTS placed near the ground and 120 CTS placed in the canopy. This CTS deployment prioritized efficient sampling at the grid-scale ensuring a high probability of detection events within the area covered by the grid. We established this camera-trapping grid at each pre-selected site considering a minimum spacing of $1 \mathrm{~km}$ when grids were in the same landscape (Fig. 1).

Arboreal camera traps were placed at $\sim 15 \mathrm{~m}$ height in the main bifurcation of large low-angle branches of canopy trees to intercept natural canopy pathways, thereby maximizing detection probability. Terrestrial camera traps were deployed on basal tree boles at $15 \mathrm{~cm}$ from the ground to ensure detection of not only large-bodied mammal and bird species, but also small-bodied rodents and marsupials (see Palmeirim et al. 2019). All CTS were unbaited, and we did not necessarily select apparently favourable terrestrial cameratrap sites (e.g. game trails) as they were deployed systematically, but we avoided major obstacles in the field of view and the understorey was slightly cleared to maximize detectability. All CTS were exposed over a minimum period of 30 camera-trap-nights (CTNs; mean \pm SD , 41.4 \pm 23.7 nights per CTS). At each CTS, we recorded the (1) camera code, (2) geographic coordinates, and (3) date and time of deployment and removal.

All photographs and videos were analysed based on species identifications. Consecutive records of the same species were defined as independent whenever they were spaced apart by intervals longer than $60 \mathrm{~min}$. For validation of species identification in case of any margin of ambiguity, 3-5 records were sent to specialists of individual taxa. Rodents and marsupials that could not be identified to species level were grouped into a single morphospecies: small $(\sim 100 \mathrm{~g})$ or very small $(\sim 15 \mathrm{~g})$ mammals. Records of domestic animals, small passerines, bats, lizards, and insects were excluded from the analyses. We extracted all photo metadata including date and time of records using the camtrapR $1.1 \mathrm{R}$ package (Niedballa et al. 2016). For data correction from cameras with programming problems, we used data obtained in the field during both camera deployment and removal. We therefore produced a database containing the total number of records per species (or morphospecies) by CTS and their respective sampling effort (hours).

\section{Vertebrate abundance and biomass}

All CTS records within any given grid were summed and divided by the total sampling effort per grid and standardized by 100 CTNs to derive a species-specific abundance index for each of the 30 grids. This index was then multiplied by the species body mass (mean adult male and female) and mean observed group size (number of individuals in 
group-living species) in the study area to obtain an approximate metric of vertebrate biomass per sampling grid.

Data on body mass were obtained from Wilman et al. (2014) and Peres (1993). Data on mean group size were derived from 3 years of monthly line-transect survey effort (Peres and Cunha 2012) along 95 terra firme and seasonally-flooded forest transects placed throughout the same Juruá meta-landscape (each of which 3-4 km in length) carried out by C.A. Peres and collaborators (unpubl. data).

Species were initially classified into either game or non-game species according to Abrahams et al. (2017) and C.A. Peres (unpubl. data), considering both commercial and subsistence hunting. All species were classed within five trophic levels based on a rank of dietary energy content (see Almeida-Rocha et al. 2017) and dietary data available in Wilman et al (2014) (Table S3). The lowest trophic level (1) thus includes species with high proportions of low-energy dietary items (i.e. foliage), whereas the highest trophic level (5) is represented by hyper-carnivores that exclusively consume vertebrates.

We also distinguished all species into either terrestrial or arboreal depending on their locomotion mode and vertical stratification according to Paglia et al. (2012). For scansorial species, which use both strata, we assigned them into the group in which they were recorded most frequently by our camera traps (Table S2). For nocturnal rodents and marsupials, we summed the species-specific biomass estimates for spiny rats (Proechimys spp.) and morphospecies identified as either small ( 100 g) or very small $(\sim 15 \mathrm{~g})$ mammals. Grid scale biomass estimates were pooled into ten functional groups that were not necessarily mutually exclusive, including (1) game species, (2) nocturnal rodents and marsupials, (3) arboreal species, (4) terrestrial species, (6) browsers, (7) grazers, (8) frugivores, (9) omnivore-insectivores, and (10) carnivores.

We opted to use a simple metric of relative abundance that does not incorporate imperfect detectability modelling (IDM) because (1) most species we sampled are naturally rare to very rare and yielded very few records; (2) this study could not count on robust temporally independent data such as in appropriate repeated-sample designs for occupancy estimation; (3) our comparisons across sites (CT grids) are largely within species and all sites shared an identical species pool, thereby reducing any potential problems of using naïve detection rates; and (4) all species were subsequently aggregated into functional groups and pooled biomass estimates were then derived for different trophic levels, so it would be inappropriate to combine different abundance estimates for those species that may or may not have enough records to perform IDM.

\section{Proxy of hunting pressure}

We built a proxy of hunting pressure based on the intensity of human activity: geographic distance to and size of human settlements, including villages and towns. Previous studies in the same area have shown that distance from urban centres represents a good proxy for the anthropogenic impact on large vertebrate abundance (Nichols et al. 2013; Abrahams et al. 2017). We measured the Euclidean distance from each camera grid centroid to all villages and the dry-season navigation (fluvial) distance to the towns using ArcGIS10.3. Human population size of each town was derived from IBGE (2018) census data, while village size was obtained from the Projeto Médio Juruá (PMJ) and the Sustainable Amazon Foundation (FAS) databases. Hunting pressure was therefore defined by the equation: 


$$
H P=\sum_{i}^{n} \frac{S(v i l)}{\sqrt{d(v i l)}}+\frac{S(c a f)}{\sqrt{d(c a f)}}+\frac{S(\text { ita })}{\sqrt{d(i t a)}}
$$

where $S$ represents the human population size at any village (vil) or towns ( $c a f=$ Carauari; ita $=$ Itamarati); $d$ represents the Euclidean distance from each grid centroid to the nearest community or the dry-season navigation (fluvial) distance to the towns.

\section{Environmental variables}

For each of the 30 sites, we compiled data on all major environmental variables that could affect vertebrate abundance and biomass besides the hunting pressure, namely (1) the proportion of várzea forest area within a $40-\mathrm{km}^{2}$ buffer area $(9.75 \mathrm{~km}$ wide) around our 30 camera-trapping grids. This was based on a 2018 Landsat 7 satellite image, which was classified using the spatial analyst tool in ArcGIS10.3; (2) water level, defined as the median Juruá River water level obtained over a 38-year time-series, corresponding to the Julian day mid-point of the camera trapping survey period within each grid. Water level data were obtained using daily readings, recorded from $1^{\text {st }}$ January 1973 to $31^{\text {st }}$ December 2010 at the nearby meteorological station of Porto Gavião, Carauari, Amazonas (ANA 2019). This variable provides a strong proxy of hydrological seasonality. Both proportion of varzea forest and water level are strongly associated with animal abundance due to the seasonal movements of terrestrial vertebrates between várzea and terra firme forests (Costa et al. 2018); and (3) soil cation exchange capacity (CEC), which we measured based on soil samples collected at each tree plot, which were analysed at the Soil Chemistry Laboratory of the National Institute for Amazon Research (INPA), Manaus. Soil chemistry analysis conducted here included major macronutrients such as $\mathrm{Ca}, \mathrm{Mg}, \mathrm{K}$ and $\mathrm{P}$ measured as cmol kg-1 which were later pooled into a single index of soil fertility. Soil fertility is a strong predictor of vertebrate biomass in Amazonian forests, particularly primary consumers (Peres 2008).

\section{Data analysis}

We examined the effects of all covariates on the aggregate vertebrate biomass for each functional group: (1) game, (2) arboreal, (3) terrestrial, and (4) nocturnal rodent and marsupials species, and (5) all five trophic guilds. In doing so, we assess the degree to which hunting pressure, water level, proportion of várzea forest and soil fertility affects the (i) aggregate biomass and (ii) community composition of birds and mammals. We removed two outlier grids (two lightly hunted sites at Tabuleiro) because these grids were unknowingly near young secondary forest areas that had been subjected to anthropogenic disturbance, so we conducted all further analysis using 28 sites.

First, we visually examined variables through histograms. Variables with non-normal distributions were transformed using the bestNormalize 1.4.2 R package (Peterson 2017), which selects the best normalization data transformation. Hunting pressure was Box-Cox transformed as well as soil fertility, and biomass estimates for small mammals, non-game species and frugivores. Likewise, biomass estimates for terrestrial, arboreal and browser species were log-transformed. Biomass of grazers and omnivore-insectivores were sqrt-transformed, whereas biomass of carnivores was Yeo-Johnson transformed. Finally, water level and proportion of várzea forest around camera-trapping grids was arcsine-transformed. We calculated the variance inflation factors (VIFs) to test for multicollinearity in explanatory variables, where 
VIFs $<4$ indicate low multicollinearity (Zuur et al. 2010). None of our explanatory variables were strongly correlated so they were all entered into generalised linear models (GLMs) with a Gaussian distribution. The spatial structure of residual models was tested using the Moran's I autocorrelation index (Gittleman and Kot 1990). All analyses were conducted in R 3.5.3 (R Development Core Team 2019).

To examine the relative importance of our environmental variables on aggregate vertebrate biomass we applied a model averaging approach using the MuMIN 1.43.15 package in R (Bartón 2016). Model averaging calculates multiple regression models from all possible combinations of variables using the dredge function and ranks models according to the Akaike`s information criteria (AIC). We considered as 'best' models those for which $\Delta \mathrm{AIC}<2$. When more than one model was selected, we built an average model using the model.avg function and determined the importance of the explanatory variables for each response variable from their frequency of occurrence in these models.

Multivariate patterns of vertebrate community composition along the gradient of hunting pressure was further investigated through Principal Coordinates Analysis (PCoA). PCoA is a method that summarises similarities or dissimilarities between multidimensional distance matrices in a low-dimensional space. We used the Bray-Curtis dissimilarity matrix to account for species identity on community composition (Legendre and Legendre 2012) based on the pcoa function in the ape $5.3 \mathrm{R}$ package (Paradis et al 2004). We first considered the (i) relative abundance, and (ii) aggregate biomass of the entire assemblage which were then subdivided into game and non-game species. Additionally, we performed a GLM with Gaussian distribution, using the environmental covariates and the hunting pressure as predictors of the scores obtained from Axes 1 and 2 of the PCoA based on the relative abundance and aggregate biomass estimates for each functional group.

To investigate changes in the size structure of both terrestrial and arboreal vertebrates along the hunting pressure gradient, we built individual-based cumulative distribution functions (CDFs) of the pooled body mass data for all independent records of each species in each camera-trapping grid (mean \pm SD per grid $=342.6 \pm 130.9$ individuals, range $=154-588$ ) As such, these CDFs calculate the cumulative probability of a given body mass value across the animal assemblage in the sampling unit (i.e., camera-trapping grid, $\mathrm{N}=28$ ). Species body mass ranged over four orders of magnitude from $15 \mathrm{~g}$ to $\sim 150,000 \mathrm{~g}$. For each CDF curve, we then calculated the total 'area under the curve' (AUC) as shown in Fig. 5. Grid scale AUC values were further used in a non-linear regression model, including a quadratic term, to investigate how this assemblage-wide metric of size structure was affected by hunting pressure. The AUC values ranged from 4.27 to 6.57. Here, higher AUC values indicate greater dominance of small- to mid-sized species, whereas lower values indicate assemblages more heavily dominated by large-bodied species. Finally, we examined shifts in size structure across the entire hunting pressure gradient based on the body mass of all terrestrial and arboreal vertebrates recorded at each trapping grid. As such, we used a mixed model approach (GLMM) in which grid identity was the random effect within which the body mass distribution of all animal records is explained by degree of hunting pressure. 


\section{Results}

\section{Arboreal and terrestrial vertebrates}

Based on 22,005 CTNs, we recorded 10,284 independent detections of 71 vertebrate species (or species groups), including 57 mammals, 13 birds and 1 reptile (Table S2). A total of 21 taxa were recorded exclusively by arboreal camera traps (5,715 CTNs), 30 exclusively by terrestrial camera traps (16,290 CTNs), and 18 were recorded by both. Terrestrial vertebrates were represented by 39 species, of which agoutis (Dasyprocta spp.) and spiny rats (Proechimys spp.) were the most abundant mammals detected, while small tinamous (Crypturellus spp.) and pale-winged trumpeters (Psophia leucoptera) were the most frequently detected birds. Collectively, these species accounted for $39.6 \%$ of all terrestrial camera trapping records.

Arboreal vertebrates were represented by 33 species, of which prehensile-tailed porcupines (Coendou spp.), large-headed capuchin monkeys (Sapajus macrocephalus), arboreal echimyid rodents, and moustached tamarins (Saguinus mystax) were most frequently detected, accounting for $41.1 \%$ of all arboreal records. Paca (Cuniculus paca), agouti (Dasyprocta spp.), collared peccary (Pecari tajacu) and grey brocket deer (Mazama nemorivaga) contributed with $50.3 \%$ of the aggregate terrestrial biomass, whereas largeheaded capuchins (S. macrocephalus), white-fronted capuchins (Cebus unicolor) and black spider monkeys (Ateles chamek) accounted for $60.5 \%$ of the aggregate canopy biomass. Considering all 71 species detected, only seven arboreal and 18 terrestrial species were habitually harvested throughout our study landscape (Table S2).

\section{Patterns of aggregate biomass}

GLM modelling showed that the aggregate biomass of most functional groups was significantly affected by site-specific hunting pressure (Fig. 2, Fig. S1). The strongest effect was observed for game species, which showed a steep decline in their aggregate biomass (Fig. 3, Table S4) at sites in the urban centre of Carauari where hunting pressure was the highest. The overall biomass of both arboreal and terrestrial vertebrate species declined in heavily hunted areas. However, while arboreal vertebrate biomass was exclusively affected by hunting pressure, biomass of terrestrial species was also positively affected by floodplain water level. Floodplain water level also showed positive effects on the biomass of grazers (Fig. 2, Table S3). Models also showed that hunting pressure had a negative effect on the aggregate biomass of grazers and frugivores (Fig. 2, Table S3 and S4). Conversely, the overall biomass of nocturnal small-bodied terrestrial rodents and marsupials, represented mostly by spiny rats, increased in heavily hunted areas compared to non-hunted areas (Fig. 3). Soil fertility positively affected the biomass of browsers and omnivores (Fig. 2).

\section{Compositional changes}

Vertebrate community structure also varied strongly in relation to site-specific hunting pressure. This pattern can be observed in ordination space by the narrow scatter in species composition and aggregate biomass at heavily hunted sites (Fig. 4). The greater convergence in community structure at sites exposed to similar levels of hunting pressure was further confirmed in GLMs by the strong relationship between the first PCoA 

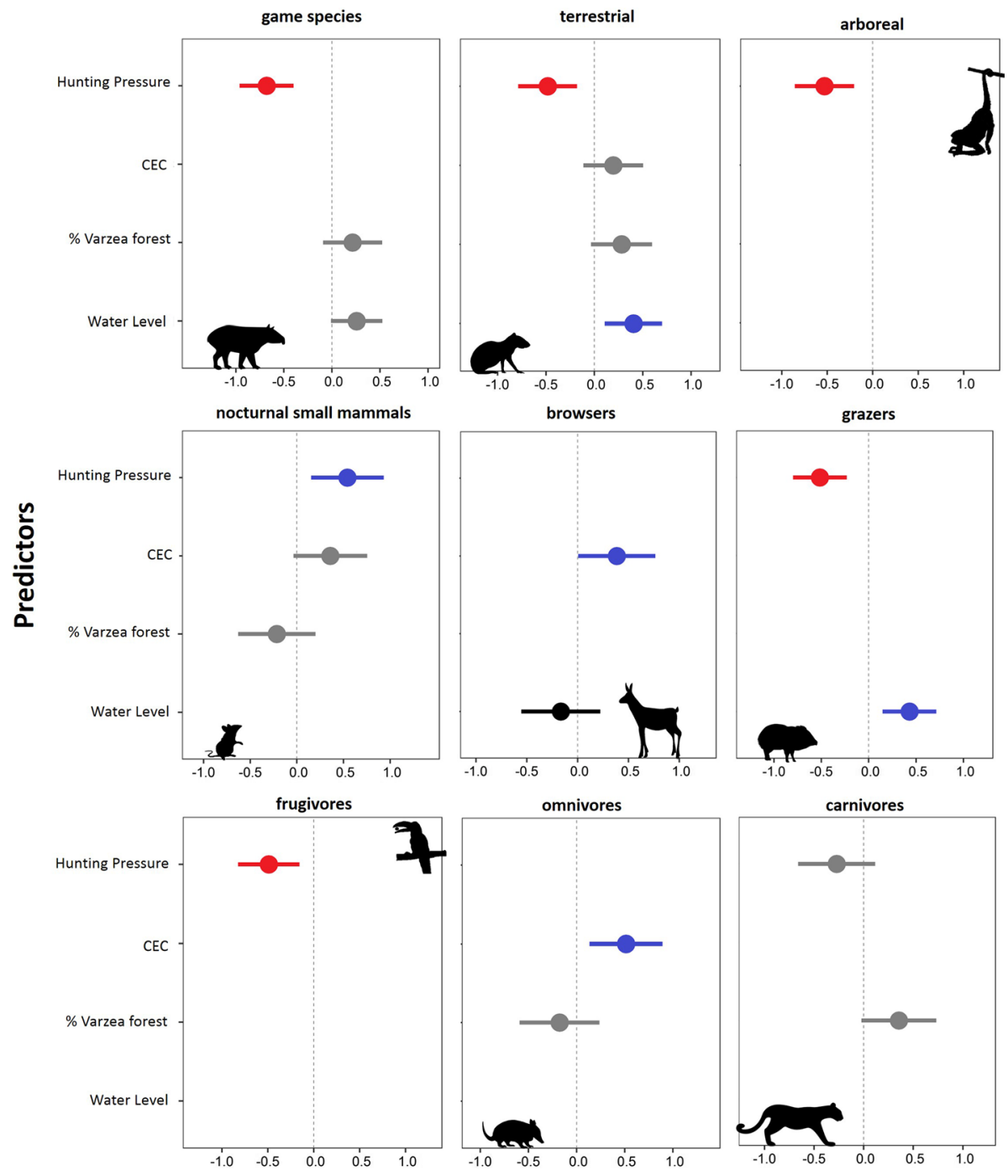

\section{Regression coefficients $\pm 95 \% \mathrm{Cl}$}

Fig. 2 Explanatory variables retained in the modelling average approach explaining the aggregate biomass of game species, terrestrial species, arboreal species, nocturnal rodents, browsers, grazers, frugivores, omnivores and carnivores. Predictor variables are listed on the left of each panel: Hunting Pressure (see text), CEC: soil cation exchange capacity, \% Várzea forest: proportion of várzea forest in relation to terra firme, and Water Level in floodplain forest. Coefficients and 95\% confidence intervals of predictors are shown in the panels. Blue and red circles indicate significantly positive and negative effect sizes, respectively, and dark grey circles indicate non-significant effects

axis and hunting pressure (Table S5). Hunting pressure significantly explained the species ordination both in terms of relative abundance and aggregate biomass. Floodplain water level was also related to the numerical abundance and biomass of vertebrates. 

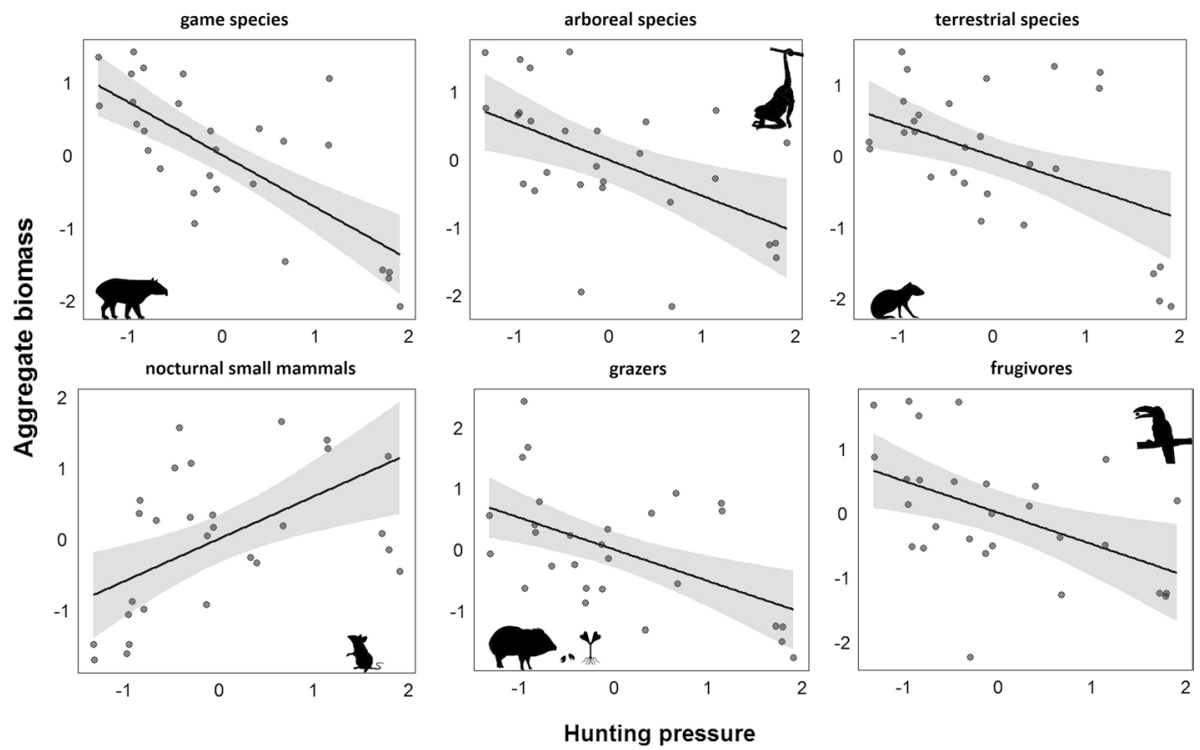

Fig. 3 Partial regression fits as a function of hunting pressure for the aggregate vertebrate biomass of functional groups, including game species, nocturnal rodents and marsupials, arboreal species, all terrestrial species, grazers, and frugivores. Y-axes show Box-Cox transformed variables. X-axes show log-transformed for game, terrestrial, and arboreal species; box-cox transformed for nocturnal small mammals and frugivores; sqrt-transformed for grazers. Grey shading along regression lines represents $95 \%$ confidence regions

\section{Assemblage-wide size structure}

The assemblage-wide vertebrate size structure across the entire harvesting gradient was downsized $~ 2.7$-fold from an average individual body mass of 1.439 [1.110-1.869] kg in our least hunted site to an average of only 0.528 [0.276-1.009] kg in our most hunted site (Fig. S2). Hunting pressure had a significantly negative effect on the body mass $\left(\log _{10} \mathrm{x}\right)$ of individual camera-trapping records (GLMM, $\beta=-0.249, \mathrm{p}=0.017$ ), assuming cameratrapping grid as a random effect. As such, we expected an increase in the area underneath each CDF function (i.e. AUCs) at sites historically exposed to persistent hunting pressure due to greater numerical dominance of small-bodied species. AUC values ranged from 5.32 in our most hunted site to 4.89 in our least hunted site. This is consistent with the fact that hunting pressure explained $34.9 \%(\mathrm{p}=0.005)$ of the variance in AUC values, which tended to be greater at more severely hunted sites (Fig. 5).

\section{Discussion}

Our study replicated across 28 terra firme sites along a marked hunting pressure gradient of western Brazilian Amazonia-spanning a wide spectrum of peri-urban, rural, and wilderness areas - shows the dominant role of hunting pressure in terms of topdown control of forest vertebrate assemblages. Post-rubber boom and contemporary hunting along the Juruá River has been primarily practiced to meet wild meat demand 

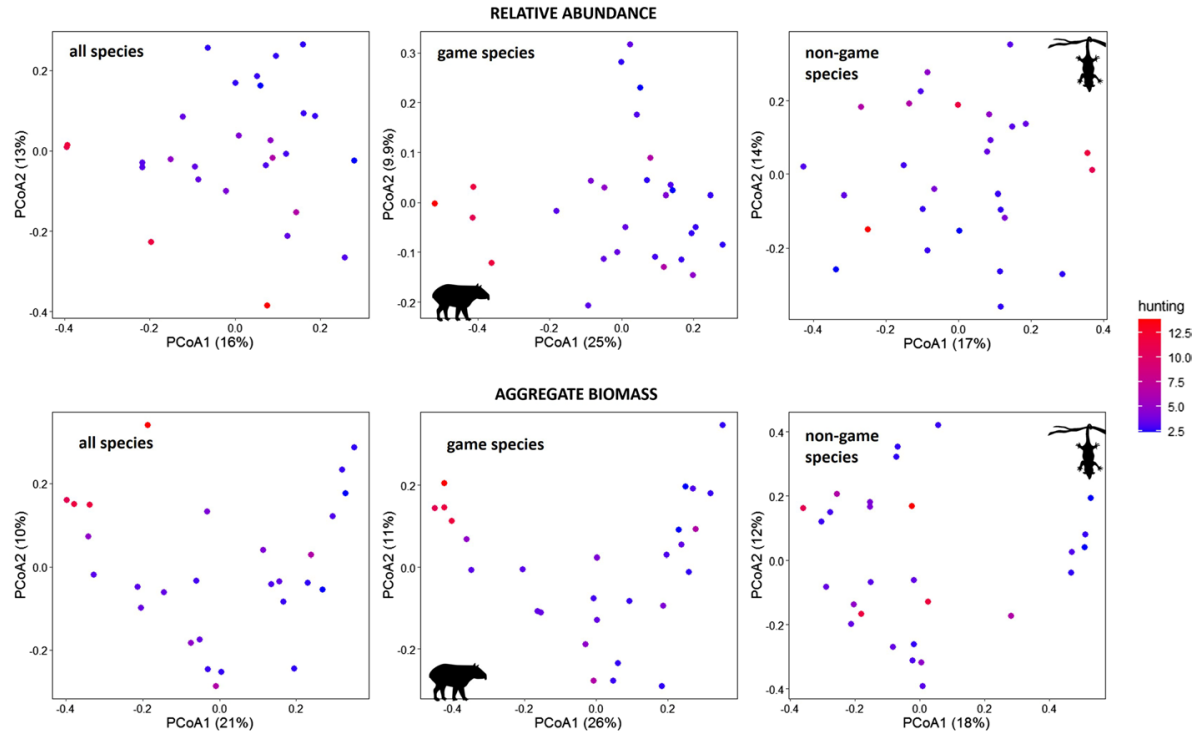

Fig. 4 Ordination based on Principal Coordinates Analysis (PCoA) using the Bray-Curtis dissimilarity matrix of vertebrate species assemblages in our study region in which level of hunting pressure increases from blue to red solid dots. Top and bottom panels show ordination plots for relative abundance and aggregate biomass, respectively. Left, central, and right panels represent all species combined, game species, and non-game species, respectively. The percentage of variance explained is reported (in brackets) for each PCoA axis

in local subsistence, rather than commercial gain (Peres 2000). In other words, the effects of historical subsistence hunting pressure were clearly more important than those of key habitat features in explaining variation in aggregate vertebrate biomass, particularly of game species. Although the effect of hunting pressure on the aggregate biomass of the entire vertebrate assemblage was significant, this effect was most pronounced in predicting the biomass and community structure of species frequently harvested by hunters.

\section{Vertebrate biomass across the hunting gradient}

Game species harvested for food along the middle section of the Juruá River, which were comprised mainly of lowland paca, collared peccary, howler monkey, spider monkey, red and grey brocket deer, and red-billed curassow (Abrahams et al. 2017), had a much greater contribution to the aggregate biomass of the vertebrate community in non-hunted areas. The game biomass contribution at the grid scale ranged from $47.8 \%$ in our least hunted site to only $6.2 \%$ in our most hunted site. This overall reduction in the biomass of large-bodied species is the first stage of a wider defaunation process described for other depleted tropical forest landscapes both across Amazonia (Peres and Palacios 2007) and elsewhere in the tropics (Benítez-López et al. 2017), and reflects the patterns of local extinctions in low-fecundity large-bodied mammals throughout the Neotropics (Bogoni et al. 2020). This may trigger several poorly 

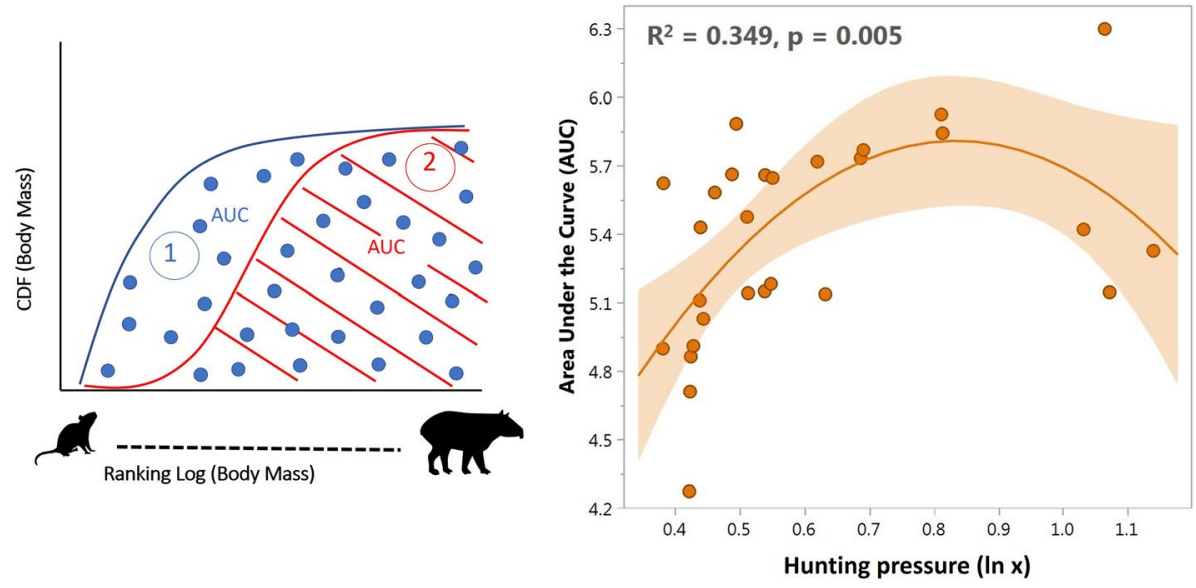

Fig. 5 Area Under the Curve (AUC) obtained using local assemblage scale cumulative distribution functions (CDF) in terms of individual vertebrate body mass and abundance built for each of our camera-trapping grids. Species body mass ranges from the smallest to the largest vertebrate species recorded within each grid (left panel). Blue and red curves represent two hypothetical body size CDFs, in which the AUC metric in (2; hatched area) is dominated by a larger proportion of large-bodied species compared to (1; blue dotted area). Non-linear regression of AUC values expressed as a quadratic function of site-specific hunting pressure (right panel). Orange shading around the regression line represents the $95 \%$ confidence interval

documented trophic cascades, including density compensation of post-dispersal seed predators, such as the apparent release of terrestrial echimyid rodents (e.g. Proechimys spp.) as documented in this study.

\section{Urban-centric hunting pressure}

Large-bodied vertebrate declines were most evident in the wider neighbourhood of the main regional scale urban centre, which was formerly a large rubber trade post. We therefore reinforce findings that large-bodied vertebrate depletion in the Amazon is primarily driven at the landscape scale, rather than by local processes alone (Abrahams et al. 2017). In other words, although populations of low-fecundity,large-bodied species are depleted near small semi-subsistence rural settlements, the highest depletion rates were evidenced in the greater peri-urban areas of larger towns (particularly within $20 \mathrm{~km}$ ) that had already been well-established trade posts well before the heyday of the rubber-boom. Sites near the smaller town of Itamarati also exhibited lower biomass estimates compared to neighbouring surveyed sites, which is consistent with a peri-urban pattern of wildlife depletion, rather than one driven by any of the other environmental gradients investigated. In any case, the overall depletion effect of the smaller town on large-bodied game biomass was considerably weaker compared to the larger town, which is older and three-fold larger in terms of human population size, thereby markedly increasing exploitation pressure on both terrestrial and aquatic resources. Surprisingly, a large village $\sim 50 \mathrm{~km}$ from Carauari and containing $\sim 650$ residents did not show marked changes in vertebrate community structure, compared to a non-hunted baseline. The aggregate hunter footprint around a large village may be appreciable, but this in itself is insufficient to irreversibly deplete harvest-sensitive game populations as long as these population centers continue to be surrounded by large 
areas of non-hunted forest. The urban-centric effect is not necessarily a result of commercial hunting pressure, as many relatively affluent urban dwellers in the Amazon continue to subsidize their households with subsistence wild meat (Chaves et al. 2017).

\section{Density compensation by nocturnal rodents}

In addition to the direct effects on game species, we also detected an indirect effect of partial defaunation on the abundance of small mammals, particularly spiny rats (Proechimys spp.) which can be highly abundant in both várzea and terra firme forest areas along the Juruá River (Malcolm et al. 2005). Elevated numbers of spiny rats in overhunted areas can likely indicate density compensation resulting from numeric depletion of large-bodied mammals, particularly grazers such as collared and white-lipped peccaries. Although small mammals have fast life histories due to high fecundity rates (Dobson and Oli 2007), and may respond rapidly to other environmental factors, our results failed to show an influence of local habitat variables and seasonality on their abundance. We therefore attribute the negative relationship between small and large-bodied mammals along the $\sim 600 \mathrm{~km}$ fluvial section of the Juruá River we surveyed to some form of competitive release, most likely of ungulates, which is consistent with similar compensatory dynamics in heavily hunted areas elsewhere in the tropics (Keesing and Young 2014; Galetti et al. 2015a).

Higher population densities of small-bodied rodents in semi-defaunated areas potentially results in several ecological and human health impacts. Higher rodent densities often favour the dominance of generalist species, thereby reducing the overall small mammal functional diversity (Pardini et al. 2009; Bovendorp et al. 2019). Furthermore, higher numbers of spiny rats likely disrupt the balance of seed predation interactions for several largeseeded plant species (Galetti et al. 2015b), which can cause a significant change in forest composition, given the importance of seed predators in maintaining plant diversity. In terms of human health, positive numerical responses in rodents may result in increases in the risk of infectious diseases for which rodents are competent reservoirs, such as hantavirus and leishmaniasis (Ashford 2000; Young et al. 2014; Muylaert et al. 2019). This would support the hypothesis that large mammal defaunation increases disease risk in humans.

\section{Vertebrate responses to hunting}

Sensitivity to hunting in arboreal mammals is consistent with the fact that hunting pressure was the only variable that strongly affected their aggregate biomass. However, there were no differences in the effect size of hunting pressure in explaining the aggregate biomass of either arboreal or terrestrial vertebrates, suggesting that both are similarly affected. This includes even large-bodied group-living arboreal mammals, such as large primates, which are noisier and more easily detectable by hunters, even though they were historically overharvested but are currently not the most preferred game species. The fact that large arboreal species are as impacted as their terrestrial counterparts suggests that populations have not yet fully recovered from a history of past hunting pressure.

Considering that primates are often high-quality dispersal agents of large-seeded plants (Chapman 1995; Lambert and Garber 1999), we suggest that reduced abundance of large primates may result in a recruitment bottleneck for at least some gut-dispersed large-seeded tree and liana species (Nunez-Iturri et al. 2008; Peres et al. 2016). In addition, we strongly 
advocate that canopy camera trapping should be used as a complementary method to linetransect surveys. This technique recorded 21 mammal species that were not detected by terrestrial camera trapping, including species that are never recorded during diurnal survey walks, such as canopy didelphids (e.g. Caluromys lanatus, Glironia venusta), and kinkajous (Potos flavus).

The aggregate biomass of terrestrial species was negatively affected by hunting pressure, but floodplain water level had a positive effect on their abundance. Strictly terrestrial vertebrates are forced to move laterally away from várzea forests and into adjacent unflooded areas as terrestrial várzea habitat is inundated each year by the rising floodwaters. These lateral movements are also related to staggered patterns of food resource availability across the várzea-terra firme interface, with ripe fruit peaks in terra firme forests occurring at the onset of the wet season (Costa et al. 2018), whereas this occurs much later during the late high-water season in várzea forests (Schongart et al. 2002; Haugaasen and Peres 2007). This likely attracts terrestrial vertebrates into neighbouring unflooded areas during the high-water season and, conversely, into seasonally-flooded forest as the water level recedes, exposing an attractive supply of fruits and seeds newly deposited on the forest floor (Haugaasen and Peres 2007). The annual flood pulse thus promotes seasonal movements in terrestrial species between várzea and terra firme forests, which can account for seasonal differences in terrestrial vertebrate abundance in the latter (Costa et al. 2018) in addition to the underlying turnover in tree community structure between these two neighbouring forest types (Hawes and Peres 2014).

Considering trophic guilds, frugivores and grazers were the only functional groups whose aggregate biomass was affected by hunting pressure. These trophic guilds play a decisive role as either seed dispersers or seed predators of large-seeded plants, thereby affecting forest regeneration and dynamics (Wright et al. 2000; Dirzo et al. 2007). Consequently, low biomass density of large-bodied frugivores can disrupt the balance between recruitment and mortality of large-seeded plants, thereby facilitating compositional transitions towards forests that are more heavily dominated by small-seeded, fast-growing species (Wright et al. 2007; Peres et al. 2016).

In this study, we did not record any white-lipped peccaries, a large-group-living ungulate forming herds as large as 500 individuals in other Amazonian forests (Haugaasen and Peres 2007) and up to 1000 individuals in the Médio Juruá region (C.A. Peres, pers. obs). This species represents an important source of protein for villagers and exerts a strong role in forest dynamics linked to seedling recruitment (Silman et al. 2003; Keuroghlian and Eaton 2009). This is likely a sampling artefact of short-term camera-trapping because herd return-times to any given area could be months, if not years, apart. A complementary method is therefore required to understand white-lipped peccary movements across vast landscapes and how they respond to hunting offtake mortality. However, local dwellers reported that white-lipped peccary herds, which cannot be overlooked, were conspicuously absent from the most hunted sites within $30 \mathrm{~km}$ of Carauari and Itamarati, thereby confirming the wildlife depletion footprint of these urban centers.

\section{Conclusion}

We have shown that even remote structurally intact Amazonian forest areas under relatively low human pressure have undergone major shifts in vertebrate community structure in both arboreal and terrestrial species wherever they fall within the depletion envelope of large 
human settlements. This suggests that marked effects of overhunting are concentrated in peri-urban areas outside protected areas, at least in landscapes that continue to benefit from healthy source-sink dynamics. Less pronounced effects of hunting within the two forest reserves were likely related to lower human population densities and low dependence on bushmeat by local dwellers for whom fish is the most important source of protein for most of the year (Endo et al. 2016; Abrahams et al. 2017).

Given the critical importance of protected areas in maintaining harvest-sensitive wildlife populations even outside their boundaries, community-based management is potentially a key strategy to reconcile wildlife conservation and food security for forest dwellers. Wildlife management strategies should be firmly grounded on applied science and consider how different patterns of defaunation may induce trophic cascade pathways that affect forest dynamics. Tried-and-tested conservation strategies that can promote hunting sustainability through community-based management remain at best embryonic (Campos-Silva et al., 2017), but this is one of the few available solutions in low-governance regions if we are to curb declines in forest wildlife and their long-term provision of ecosystem services.

Supplementary Information The online version contains supplementary material available at https://doi. org/10.1007/s10531-021-02266-9.

Acknowledgements AcknowledgmentsWe are grateful to Associação dos Produtores Rurais de Carauari (ASPROC), Centro Estadual de Unidades de Conservação do Amazonas (CEUC/SDS/AM), Instituto Chico Mendes de Conservação da Biodiversidade (ICMBio), Operação Amazônia Nativa (OPAN) and Projeto Médio Juruá (PMJ) for support on fieldwork logistics. Instituto Nacional de Pesquisas da Amazônia (INPA) for support on laboratory analysis. Finally, we are grateful to all local villagers of the RESEX Médio Juruá and RDS Uacari and dwellers of Carauari and Itamarati for their hospitality, friendship and trust.

Author Contributions Conceptualization: [ABS, CAP]; Funding acquisition [ABS]; Data collection [ABS]; Formal analysis and investigation $[\mathrm{ABS}, \mathrm{CAP}]$; Writing —original draft preparation $[\mathrm{AB} \mathrm{S}]$, Writingreview and editing [CAP]; Supervision [CAP].

Funding This work was supported by the National Geographic Society [grant number: 265943], Rufford Foundation [Grant Number: 21911-1], Society for Conservation Biology [LACA Professional Development Award], and a DEFRA/UK (Darwin Initiative for the Survival of Species) grant [Project 20-001] awarded to CAP. ABS was granted a PhD studentship from Coordenação de Aperfeiçoamento de Pessoal de Nível Superior - Brasil (CAPES) [Finance Code 001].

Data Availability The datasets generated during and/or analysed during the current study are available from the corresponding author on reasonable request.

Open Access This article is licensed under a Creative Commons Attribution 4.0 International License, which permits use, sharing, adaptation, distribution and reproduction in any medium or format, as long as you give appropriate credit to the original author(s) and the source, provide a link to the Creative Commons licence, and indicate if changes were made. The images or other third party material in this article are included in the article's Creative Commons licence, unless indicated otherwise in a credit line to the material. If material is not included in the article's Creative Commons licence and your intended use is not permitted by statutory regulation or exceeds the permitted use, you will need to obtain permission directly from the copyright holder. To view a copy of this licence, visit http://creativecommons.org/licenses/by/4.0/.

\section{References}

Abernethy KA, Coad L, Taylor G et al (2013) Extent and ecological consequences of hunting in Central African rainforests in the twenty-first century. Philos Trans R Soc B. https://doi.org/10.1098/rstb.2012. 0303 
Abrahams MI, Peres CA, Costa HCM (2017) Measuring local depletion of terrestrial game vertebrates by central-place hunters in rural Amazonia. PLoS ONE 12:1-25. https://doi.org/10.1371/journal.pone. 0186653

ANA (2019) Agencia Nacional das Aguas (ANA). https://www.ana.gov.br/. Accessed 3 Mar 2021

Antunes AP, Fewster RM, Venticinque EM et al (2016) Empty forest or empty rivers? A century of commercial hunting in Amazonia. Sci Adv. https://doi.org/10.1126/sciadv.1600936

Ashford RW (2000) The leishmaniases as emerging and reemerging zoonoses. Int J Parasitol 30:1269-1281. https://doi.org/10.1016/B978-0-12-803265-7.00007-5

Assis RL, Haugaasen T, Schöngart J et al (2015) Patterns of tree diversity and composition in Amazonian floodplain paleo-várzea forest. J Veg Sci 26:312-322. https://doi.org/10.1111/jvs.12229

Bartón K (2016) MuMIn - Multi-model inference. R package version, 1(6)

Benítez-López A, Alkemade R, Schipper AM et al (2017) The impact of hunting on tropical mammal and bird populations. Science (80-) 356:180-183. https://doi.org/10.1126/science.aaj1891

Benítez-López A, Santini L, Schipper AM et al (2019) Intact but empty forests? Patterns of hunting-induced mammal defaunation in the tropics. PLoS Biol 17:1-18. https://doi.org/10.1371/journal.pbio.3000247

Bogoni J, Ferraz K, Peres CA (2020) Extent, intensity and drivers of mammal defaunation: a continentalscale analysis across the neotropics. Nat Sci Rep 10:1-16

Bovendorp RS, Brum FT, McCleery RA et al (2019) Defaunation and fragmentation erode small mammal diversity dimensions in tropical forests. Ecography (cop) 42:23-35. https://doi.org/10.1111/ecog. 03504

Bowler MT, Tobler MW, Endress BA et al (2017) Estimating mammalian species richness and occupancy in tropical forest canopies with arboreal camera traps. Remote Sens Ecol Conserv 3:146-157. https://doi. org/10.1002/rse2.35

Campos-Silva JV, Peres CA, Antunes AP et al (2017) Community-based population recovery of overexploited Amazonian wildlife. Perspect Ecol Conserv 15:266-270. https://doi.org/10.1016/j.pecon.2017. 08.004

Chapman CA (1995) Primate seed dispersal: coevolution and conservation implications. Evol Anthropol Issues News Rev 4:74-82. https://doi.org/10.1002/evan.1360040303

Chaves WA, Wilkie DS, Monroe MC, Sieving KE (2017) Market access and wild meat consumption in the central Amazon, Brazil. Biol Conserv 212:240-248. https://doi.org/10.1016/j.biocon.2017.06.013

Costa HCM, Peres CA, Abrahams MI (2018) Seasonal dynamics of terrestrial vertebrate abundance between Amazonian flooded and unflooded forests. PeerJ 6:e5058. https://doi.org/10.7717/peerj.5058

Dirzo R, Mendoza E, Ortíz P (2007) Size-related differential seed predation in a heavily defaunated neotropical rainforest. Biotropica 39:355-362. https://doi.org/10.1111/j.1744-7429.2007.00274.x

Dobson FS, Oli MK (2007) Fast and slow life histories of mammals. Ecoscience 14:292-297. https://doi. org/10.1139/z11-033

de Almeida-Rocha JM, Peres CA, Oliveira LC (2017) Primate responses to anthropogenic habitat disturbance: a pantropical meta-analysis. Biol Conserv 215:30-38. https://doi.org/10.1016/j.biocon.2017.08. 018

Endo W, Peres CA, Haugaasen T (2016) Flood pulse dynamics affects exploitation of both aquatic and terrestrial prey by Amazonian floodplain settlements. Biol Conserv 201:129-136. https://doi.org/10. 1016/j.biocon.2016.07.006

Fa JE, Brown D (2009) Impacts of hunting on mammals in African tropical moist forests: a review and synthesis. Mamm Rev 39:231-264. https://doi.org/10.1111/j.1365-2907.2009.00149.x

Fa JE, Peres CA, Meeuwig J (2002) Bushmeat exploitation in tropical forests: an intercontinental comparison. Conserv Biol 16:232-237. https://doi.org/10.1046/j.1523-1739.2002.00275.x

Fragoso JMV, Levi T, Oliveira LFB et al (2016) Line transect surveys underdetect terrestrial mammals: Implications for the sustainability of subsistence hunting. PLoS ONE 11:1-18. https://doi.org/10.1371/ journal.pone.0152659

Galetti M, Bovendorp RS, Guevara R (2015a) Defaunation of large mammals leads to an increase in seed predation in the Atlantic forests. Glob Ecol Conserv 3:824-830

Galetti M, Guevara R, Neves CL et al (2015b) Defaunation affect population and diet of rodents in Neotropical rainforests. Biol Conserv 190:2-7. https://doi.org/10.1016/j.biocon.2015.04.032

Gittleman JL, Kot M (1990) Adaptation: statistics and a null model for estimating phylogenetic effects. Syst Zool 39:227-241

Harrison RD, Sreekar R, Brodie JF et al (2016) Impacts of hunting on tropical forests in Southeast Asia. Conserv Biol 30:972-981. https://doi.org/10.1111/cobi.12785

Haugaasen T, Peres CA (2007) Vertebrate responses to fruit production in Amazonian flooded and unflooded forests. Biodivers Conserv 16:4165-4190. https://doi.org/10.1007/s10531-007-9217-z 
Hawes JE, Peres CA (2014) Fruit-frugivore interactions in Amazonian seasonally flooded and unflooded forests. J Trop Ecol 30:381-399. https://doi.org/10.1017/S0266467414000261

Hawes JE, Peres CA (2016) Patterns of plant phenology in Amazonian seasonally flooded and unflooded forests. Biotropica 48:465-475. https://doi.org/10.1111/btp.12315

IBGE (2018) Instituto Brasileiro de Geografia e Estatística (IBGE). In: Censo 2018. https://www.ibge. gov.br/

Jerozolimski A, Peres CA (2003) Bringing home the biggest bacon: a cross-site analysis of the structure of hunter-kill profiles in Neotropical forests. Biol Conserv 111:415-425. https://doi.org/10.1016/ S0006-3207(02)00310-5

Keesing F, Young TP (2014) Cascading consequences of the loss of large mammals in an African Savanna. Bioscience 64:487-495. https://doi.org/10.1093/biosci/biu059

Keuroghlian A, Eaton DP (2009) Removal of palm fruits and ecosystem engineering in palm stands by white-lipped peccaries (Tayassu pecari) and other frugivores in an isolated Atlantic Forest fragment. Biodivers Conserv 18:1733-1750. https://doi.org/10.1007/s10531-008-9554-6

Lambert JE, Garber PA (1999) Evolutionary and ecological implications of primate seed dispersal. Am J Primatol 45:9-28

Legendre P, Legendre L (2012) Numerical ecology, 3rd English edition. Elsevier Science BV, Amsterdam

Malcolm JR, Patton JL, da Silva MNF (2005) Small mammal communities in upland and floodplain forests along an Amazonian white-water river. In: Lacey EI, Myers P (eds) Mammalian diversification: From chromosomes to phylogeography, UC Publications in Zoology Paper, Berkley, CA, pp 335-380

Michalski F, Boulhosa RLP, Faria A, Peres CA (2006) Human-wildlife conflicts in a fragmented Amazonian forest landscape: determinants of large felid depredation on livestock. Anim Conserv 9:179188. https://doi.org/10.1111/j.1469-1795.2006.00025.x

Muylaert RL, Sabino-Santos G, Prist PR et al (2019) Spatiotemporal dynamics of hantavirus cardiopulmonary syndrome transmission risk in Brazil. Viruses. https://doi.org/10.3390/v11111011

Nichols E, Uriarte M, Peres CA et al (2013) Human-induced trophic cascades along the fecal detritus pathway. PLoS ONE. https://doi.org/10.1371/journal.pone.0075819

Niedballa J, Sollmann R, Courtiol A, Wilting A (2016) camtrapR: an R package for efficient camera trap data management. Methods Ecol Evol 7:1457-1462. https://doi.org/10.1111/2041-210X.12600

Nielsen MR, Meilby H, Smith-Hall C et al (2018) The importance of wild meat in the global south. Ecol Econ 146:696-705. https://doi.org/10.1016/j.ecolecon.2017.12.018

Nunes AV, Peres CA, de Constantino PAL et al (2019) Irreplaceable socioeconomic value of wild meat extraction to local food security in rural Amazonia. Biol Conserv 236:171-179. https://doi.org/10. 1016/j.biocon.2019.05.010

Nunez-Iturri G, Olsson O, Howe HF (2008) Hunting reduces recruitment of primate-dispersed trees in Amazonian Peru. Biol Conserv 141:1536-1546. https://doi.org/10.1016/j.biocon.2008.03.020

Paglia AP, Fonseca GAB, Herrmann G, et al (2012) Lista anotada dos mamíferos do Brasil. 2nd Edition. Occasional Papers in Conservation Biology 6. Washington: Conservation International. 76p.

Palmeirim AF, Benchimol M, Peres CA, Vieira MV (2019) Moving forward on the sampling efficiency of neotropical small mammals: insights from pitfall and camera trapping over traditional live trapping. Mamm Res 64:445-454. https://doi.org/10.1007/s13364-019-00429-2

Paradis E, Claude J, Strimmer K (2004) APE: an R package for analyses of phylogenetics and evolution. Bioinformatics 20:289-290

Pardini R, Faria D, Accacio GM et al (2009) The challenge of maintaining Atlantic forest biodiversity: a multi-taxa conservation assessment of specialist and generalist species in an agro-forestry mosaic in southern Bahia. Biol Conserv 142:1178-1190. https://doi.org/10.1016/j.biocon.2009.02.010

Peres CA (1993) Notes on the primates of the Juruá River, Western Brazilian Amazonia. Folia Primatol 61:97-103. https://doi.org/10.1159/000156735

Peres CA (2000) Effects of subsistence hunting on vertebrate community structure in Amazonian forests. Conserv Biol 14:240-253. https://doi.org/10.1046/j.1523-1739.2000.98485.x

Peres CA (2008) Soil fertility and arboreal mammals biomass in tropical forest. In: S Schnitzer and W Carson (eds) Tropical forest community ecology. Blackwell Scientific, Oxford

Peres CA (2012) Line-transect censuses of large-bodied tropical forest vertebrates: a Handbook. Wildlife Conservation Society, Brasília

Peres CA, Dolman PM (2000) Density compensation in neotropical primate communities: evidence from 56 hunted and nonhunted Amazonian forests of varying productivity. Oecologia 122:175-189. https://doi.org/10.1007/PL00008845 
Peres CA, Lake IR (2003) Extent of nontimber resource extraction in tropical forests: accessibility to game vertebrates by hunters in the amazon basin. Conserv Biol 17:521-535. https://doi.org/10. 1046/j.1523-1739.2003.01413.x

Peres CA, Palacios E (2007) Basin-wide effects of game harvest on vertebrate population densities in Amazonian forests: implications for animal-mediated seed dispersal. Biotropica 39:304-315. https://doi.org/10.1111/j.1744-7429.2007.00272.x

Peres CA, Roosmalen M van (2009) Primate frugivory in two species-rich neotropical forests: implications for the demography of large-seeded plants in overhunted areas. In Levey D, Silva W, Galetti M (eds) Seed dispersal and frugivory: ecology, evolution and conservation. CABI International, Oxford, pp $407-423$

Peres CA, Emilio T, Schietti J et al (2016) Dispersal limitation induces long-term biomass collapse in overhunted Amazonian forests. Proc Natl Acad Sci USA 113:892-897. https://doi.org/10.1073/ pnas. 1516525113

Peterson RA (2017) bestNormalize: Normalizing transformation functions. R package V.1.4.2

R Development Core Team (2019) R: A language and environment for statistical computing. Version 3.5.3. R Foundation, Vienna

Redford KH (1992) The Empty forest. Bioscience 42:412-422. https://doi.org/10.2307/1311860

Ripple WJ, Newsome TM, Wolf C et al (2015) Collapse of the world's largest herbivores. Sci Adv. https:// doi.org/10.1126/sciadv.1400103

Schongart J, Piedade MTF, Ludwigshausen S et al (2002) Phenology and stem-growth periodicity of tree species in Amazonian floodplain forests. J Trop Ecol 18:581-597. https://doi.org/10.1017/S026646740 2002389

Silman MR, Terborgh JW, Kiltie RA (2003) Population regulation of a dominant rain forest tree by a major seed predator. Ecology 84:431-438. https://doi.org/10.1890/0012-9658(2003)084[0431:PROADR]2.0. $\mathrm{CO} ; 2$

Whitworth A, Braunholtz LD, Huarcaya RP et al (2016) Out on a limb: Arboreal camera traps as an emerging methodology for inventorying elusive rainforest mammals. Trop Conserv Sci 9:675-698. https:// doi.org/10.1177/194008291600900208

Whitworth A, Macleod R, Beirne C et al (2019) Human disturbance impacts on rainforest mammals are most notable in the canopy, especially for larger-bodied species. Diversity Distrib. https://doi.org/10. 1111/ddi.12930

Wilkie DS, Bennett EL, Peres CA, Cunningham AA (2011) The empty forest revisited. Ann N Y Acad Sci 1223:120-128. https://doi.org/10.1111/j.1749-6632.2010.05908.x

Wilman H, Belmaker J, Jennifer S et al (2014) EltonTraits 1.0: species-level foraging attributes of the world 's birds and mammals. Ecology 95:2027. https://doi.org/10.1890/13-1917.1

Wright SJ, Zeballos H, Dominguez I et al (2000) Poachers alter mammal abundance, seed dispersal, and seed predation in a neotropical forest. Conserv Biol 14:227-239. https://doi.org/10.1046/j.1523-1739. 2000.98333.X

Wright SJ, Stoner KE, Beckman N et al (2007) The plight of large animals in tropical forests and the consequences for plant regeneration. Biotropica 39:289-291. https://doi.org/10.1111/j.1744-7429.2007. 00293.x

Young HS, Dirzo R, Helgen KM et al (2014) Declines in large wildlife increase landscape-level prevalence of rodent-borne disease in Africa. Proc Natl Acad Sci USA 111:7036-7041. https://doi.org/10.1073/ pnas. 1404958111

Young HS, Mccauley DJ, Dirzo R, Goheen JR (2015) Context-dependent effects of large wildlife declines on small mammal communities in central Kenya. Ecol Soc Am 25:348-360

Zuur AF, Ieno EN, Elphick CS (2010) A protocol for data exploration to avoid common statistical problems. Methods Ecol Evol 1:3-14. https://doi.org/10.1111/j.2041-210x.2009.00001.x

Publisher's Note Springer Nature remains neutral with regard to jurisdictional claims in published maps and institutional affiliations. 


\section{Authors and Affiliations}

\section{Andressa B. Scabin ${ }^{1,2}$ (D) Carlos A. Peres ${ }^{2,3}$ (D)}

1 Programa de Pós-Graduação Em Ecologia, Universidade Federal Do Rio Grande Do Norte, Natal, RN, Brazil

2 Instituto Juruá, Rua das Papoulas, 97 Aleixo, Manaus, AM, Brazil

3 Centre for Ecology, Evolution and Conservation, School of Environmental Sciences, University of East Anglia, Norwich, UK 